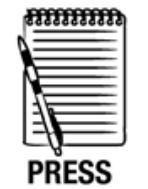

RELEASE

12Division of Epidemiology and Public Health, University of Nottingham, Nottingham, UK ${ }^{2}$ Division of General Internal Medicine, San Francisco General Hospital, University of California, San Francisco, California, USA ${ }^{3}$ Department of Primary Care and Social Medicine, Imperial College, London, UK

${ }^{4}$ Onbeyond LLC, Fairfax, California, USA

${ }^{5}$ Division of Cardiology, University of California, San Francisco, California, USA

${ }^{6}$ Center for Tobacco Control Research and Education, University of California, San Francisco, California, USA

\section{Correspondence to}

Professor Stanton A Glantz, Center for Tobacco Control Research and Education, University of California, San Francisco, Box 1390, Room 366, 530 Parnassus, San Francisco, CA 94143-1390, USA

Received 24 November 2009 Accepted 7 January 2010

\title{
Exposure to smoking in movies among British adolescents 2001-2006
}

\author{
Stacey J Anderson, ${ }^{1}$ Christopher Millett, ${ }^{2,3}$ Jonathan R Polansky, ${ }^{4}$ Stanton A Glantz ${ }^{5,6}$
}

\begin{abstract}
Objective To estimate youth exposure to smoking in movies in the UK and compare the likely effect with the USA.

Methods We collected tobacco occurrences data for 572 top-grossing films in the UK screened from 2001 to 2006 and estimated the number of on-screen tobacco impressions delivered to British youths in this time period.
\end{abstract}

Results $91 \%$ of films in our sample that contained smoking were youth-rated films (British Board of Film Classification rating ' 15 ' and lower), delivering at least 1.10 billion tobacco impressions to British youths during theatrical release. British youths were exposed to $28 \%$ more smoking impressions in UK youth-rated movies than American youth-rated movies, because $79 \%$ of movies rated for adults in the USA (' $R$ ') are classified as suitable for youths in the UK ('15' or '12A').

Conclusion Because there is a dose-response relation between the amount of on-screen exposure to smoking and the likelihood that adolescents will begin smoking, the fact that there is substantially higher exposure to smoking in youth-rated films in the UK than in the USA suggests that the fraction of all youth smoking because of films in the UK is probably larger than in the USA. Other countries with ratings systems that are less conservative (in terms of language and sexuality) than the USA will also be likely to deliver more on-screen tobacco impressions to youths. Assigning an '18' classification to movies that contain smoking would substantially reduce youth exposure to on-screen smoking and, hence, smoking initiation among British youths.

\section{INTRODUCTION}

Exposure to on-screen smoking in movies causes youths to smoke. ${ }^{1-5}$ There is a 'dose-response': the more smoking youths see, the more likely they are to smoke, with heavily exposed youths about three times as likely to begin smoking as lightly exposed youths, after controlling for other factors linked with smoking (peer smoking, parental smoking, academic performance, exposure to cigarette advertising and other factors). ${ }^{6}$ These results from the USA have been confirmed both qualitatively and quantitatively in New Zealand, ${ }^{7}$ Mexico $^{8}$ and Germany. ${ }^{9-11}$ (One study using secondary data analysis from Scotland found no effect, ${ }^{12}$ but the authors noted that there may be problems in exposure assessment which biases the results towards the null.) Concern over the effects of onscreen smoking on adolescent smoking initiation has led many organisations, including the British Medical Association, ${ }^{3}$ Institute of Medicine of the US National Academy of Sciences ${ }^{2}$ and the World Health Organization ${ }^{13}$ to call for reductions in youth exposure to on-screen smoking. Addressing the fact that on-screen smoking promotes youth smoking is part of implementing the WHO Framework Convention on Tobacco Control. ${ }^{13}$

One way to reduce exposure would be to integrate tobacco imagery into national film ageclassification systems to give films depicting tobacco an adult content rating. ${ }^{13} 14$ The British Board of Film Classification (BBFC), the non-governmental, film industry-funded agency that recommends ratings for films in the UK, states that a rating of '18', which precludes people under 18 from seeing a film in a cinema, should be awarded to films "where material or treatment appears to the Board to risk harm to individuals or, through their behaviour, to society', ${ }^{15}$ a standard met by the available scientific evidence on the effect of on-screen smoking on youth behaviour. As of February 2010 the BBFC had refused to apply its rules to on-screen smoking.

The BBFC is, however, only advisory to local councils. The BBFC notes, '[s]tatutory powers on film remain with the local councils, which may over-rule any of the Board's decisions, passing films we reject, banning films we have passed, and even waiving cuts, instituting new ones, or altering categories for films exhibited under their own licensing jurisdiction'. ${ }^{16}$ Because of the BBFC's failure to act, in 2008 Liverpool announced it was considering applying an '18' rating to films with tobacco use ${ }^{517}$ and on 12 June 2009 initiated the formal consultation process to integrate this policy into its local licensing procedure. ${ }^{18}$

To estimate the potential effect of such a policy, we estimated the level of exposure to smoking in youth rated (BBFC ratings $\mathrm{U}, \mathrm{PG}, 12 \mathrm{~A}$ and 15 ) films.

\section{METHODS}

\section{Amount of smoking in films in the UK market}

There were 738 motion pictures in the top 10 weekly box office lists for 1 January 2001-31 December 2006 that earned at least $\$ 250000$ in the $\mathrm{UK}^{19}$ (excluding ET, The Extraterrestrial, a 1982 film, and Alien, a 1979 film, re-released during the study period). We obtained the number of tobacco occurrences in 572 films (546 top grossing films in the UK that also ran in the USA, and 26 top grossing films in the UK market not released to US theatres) from the Cancer Control Research Program at DartmouthHitchcock Medical Center using the same established methods ${ }^{20}$ as have been used for the epidemiological studies of the effects of on-screen smoking on adolescent ${ }^{6-12} 21-23$ and young adult ${ }^{24}$ smoking behaviour.

Briefly ${ }^{20}$ trained coders reviewed each film, recorded 'tobacco episodes', defined as the appearance of tobacco use or handling of tobacco products unlocked scheme, see http:/ about/unlocked.xhtml 
by a major or minor character in one scene (with two people smoking in the same scene counting as two episodes) and 'tobacco incidents', defined as the appearance of tobacco in a scene without use by a character (with all such 'incidents' in a single scene coded as one incident). 'Tobacco occurrences' are the sum of tobacco episodes plus tobacco incidents in a film.

\section{Tobacco impressions delivered by movies in theatrical release}

The number of 'tobacco impressions' delivered by a film is a measure of its impact promoting adolescent tobacco use. One impression is one person seeing one tobacco occurrence one time.

We obtained the average ticket price for each of the years in our study (2001-2006) from the UK Film Council ${ }^{25}$ and divided the total box office earnings of each film by the year's average ticket price, yielding the estimated number of in-theatre views of each film. We multiplied the number of views by the tobacco occurrences to estimate the 'tobacco impressions' delivered to UK cinema-going audiences by each film.

We obtained statistics for movie attendance by rating and by age for the years 2005-2007 from the UK Film Council. ${ }^{25}$ The fraction of the audience comprising children and adolescents ages 7-17 remained stable over this period, so we used average fractions of ticket sales for each rating (' $U$ ': $37.7 \%$, 'PG': 36.3\%, '12A': $27.0 \%$, '15': $16.7 \%$ ) to estimate tobacco impressions delivered to children and adolescents (box 1 provides an example of this calculation).

We performed similar calculations after dividing the films based on the US (Motion Picture Association of America, MPAA) rating scheme. ${ }^{17}$ We compared smoking occurrences and impressions in US, UK and European produced films.

\section{RESULTS}

\section{Tobacco occurrences in films rated for youths}

Of the 572 films in this 2001-2006 sample (table 1), 396 (69\%) featured tobacco. Of films depicting tobacco, 359 (91\%) received a UK youth rating (BBFC '15' and below). Of the 3808 tobacco

\section{Box 1 Example of calculation of youth exposure to}

\section{smoking in a specific film}

- The Terminal, a 2004 film, grossed $£ 6052047$ during its run. The average ticket price in 2004 was $£ 4$.49. Dividing 6052047 by 4.49 gives us 1347895 estimated total in-theatre views of this film. There were nine tobacco occurrences in this film, hence 12131055 tobacco impressions (1347 895 $\times 9)$ delivered to UK cinema audiences.

- This film was classified ' $12 \mathrm{~A}$ ' by the BBFC. According to the UK Film Council, $27.0 \%$ of audiences viewing films classified ' $12 A$ ' were aged $7-17$. Therefore, we multiplied the total tobacco impressions $(12131055)$ by 0.27 to obtain 3275385 impressions delivered to youths aged $7-17$ by The Terminal during its theatrical run.

- We summed total impressions delivered to youths aged 7-17 by all films classified ' $12 A$ ' to obtain a total estimate of youth exposure by films with that classification.

- We performed these calculations for each of the film classification categories to obtain estimates of youth exposure by films classified ' $U$ ' or 'PG', '12A' and '15A'. The UK Film Council does not collect youth attendance data for films classified ' $18 \mathrm{~A}$ ', so we were not able to obtain exposure estimates for films classified ' $18 A$ '. occurrences presented by this 2001-2006 film sample, 3308 $(87 \%)$ were in UK youth-rated films. The films in this sample delivered a total of 5.07 billion tobacco impressions to UK cinema audiences; 4.49 billion (89\%) of these impressions were delivered in youth-rated films. Over the time period studied, youth-rated films delivered 1.09 billion tobacco impressions while in theatrical release to UK children and adolescents aged $7-17$ years.

For comparison, $45 \%$ of the tobacco occurrences in the sample were in films that the US MPAA gave a youth rating (G, PG or PG-13), whereas $87 \%$ were in films that the BBFC gave a youth rating. Because $79 \%$ of movies rated for adults in the USA ('R') are classified as suitable for youths in the UK ('15' or ' $12 \mathrm{~A}$ '), British youths were exposed to $28 \%$ more smoking impressions in UK youth-rated movies than in American youth-rated films (1.09 billion tobacco impressions vs 850 million, both based on UK audience youth composition data). Although UK-produced films contained more tobacco occurrences on average than US-produced films, the dominance of US-produced films in the cinema market means US studios were responsible for the vast majority of tobacco impressions delivered to UK audiences.

\section{DISCUSSION}

The vast majority of smoking events in films shown in the UK was delivered by youth-rated films (89\%). Although US film studios were responsible for almost all of the movies with smoking events viewed in the UK (96\%), more smoking occurs in films rated for youths in the UK (6.22 average occurrences) than occurs in youth-rated films in the USA (4.50 average occurrences). This difference is mainly because the large number of films rated ' $R$ ' in the USA (under 17 not admitted without parent or guardian) are re-classified as ' 15 ' in the UK. Of 190 films rated ' $\mathrm{R}$ ' by the MPAA in the USA, BBFC assigned 21\% an ' 18 ', $77 \%$ a ' 15 ' rating and $2 \%$ a ' $12 \mathrm{~A}$ ' rating. More smoking appears in US ' $R$ '-rated films than appears in films rated for youths; assigning such films a youth classification in the UK means British youths have greater potential exposure to smoking in movies. In both the UK and USA, youth-rated films comprise the majority of films with smoking and deliver the majority of tobacco impressions to theatre audiences: unsurprising, since US films dominate the UK market. In the UK, however, because of $\mathrm{BBFC}$ rating practice, the share of tobacco occurrences seen in youth-rated films (87\%) is nearly twice that in the USA (45\%). Other countries (eg, Germany ${ }^{10}$ ) with ratings systems that are less conservative (in terms of language and sexuality) than the USA will also be likely to deliver more on-screen tobacco impressions to youths.

Four studies in the USA have estimated the attributable risk fraction of adolescent and young adult smokers, three based on northern New England longitudinal studies ${ }^{622} 23$ and one based on a national cross-sectional study, ${ }^{21}$ all of which used multivariate models, so they control for confounding. The original New England cohort $^{6}$ (middle school students at baseline) found that 0.52 (95\% CI 0.30 to 0.67 ) of those who 'tried smoking' was attributable to smoking in the movies. A later follow-up in the same cohort ${ }^{23}$ found an attributable risk fraction of 0.35 (95\% CI 0.14 to 0.56 ) for established smoking at young adulthood because of movie smoking exposure. A different northern New England longitudinal cohort $^{22}$ that started with younger children (4th-6th graders at baseline) found that 0.46 (95\% CI 0.11 to 0.70 ) of youths who tried smoking was attributable to movie exposure. Finally a national cross-sectional study ${ }^{21}$ (adolescents 10-14 years old) found that the adjusted attributable fraction for having tried smoking was 0.38 (95\% CI 0.20 to 0.56$)$. It is likely that the attributable risk fractions in the UK would be higher 
Table 1 Level of exposure to on-screen smoking by BBFC and MPAA classification, 2001-2006

\begin{tabular}{|c|c|c|c|c|c|c|c|c|c|c|}
\hline & \multicolumn{5}{|c|}{ BBFC classification } & \multicolumn{4}{|c|}{ MPAA classification } & \multirow[b]{2}{*}{ Tota } \\
\hline & U/PG & $12 A$ & 15 & 18 & $\begin{array}{l}\text { UK } \\
\text { Total youth } \\
\text { rated }^{*} \ddagger\end{array}$ & G/PG & PG-13 & $\mathbf{R}$ & $\begin{array}{l}\text { USA } \\
\text { Total youth } \\
\text { rated } \dagger \neq\end{array}$ & \\
\hline Total films & 145 & 199 & 188 & 40 & 532 & 119 & 263 & 190 & 382 & 572 \\
\hline Films with tobacco & 58 & 148 & 153 & 37 & 359 & 40 & 192 & 164 & 232 & 396 \\
\hline \multicolumn{11}{|l|}{ Occurrences } \\
\hline UK-produced & 1 & 39 & 37 & 22 & 77 & 16 & 10 & 73 & 26 & 99 \\
\hline US-produced & 315 & 1149 & 1701 & 464 & 3165 & 202 & 1486 & 1941 & 1688 & 3629 \\
\hline Other produced & 6 & 0 & 60 & 14 & 66 & 0 & 6 & 74 & 6 & 80 \\
\hline Total & 322 & 1188 & 1798 & 500 & 3308 & 218 & 1502 & 2088 & 1720 & 3808 \\
\hline \multicolumn{11}{|c|}{ Impressions (millions) } \\
\hline UK-produced & 0.4 & 10 & 20 & 20 & 30 & 6 & 9 & 40 & 20 & 50 \\
\hline US-produced & 750 & 1900 & 1770 & 570 & 4420 & 290 & 2690 & 2020 & 2980 & 5000 \\
\hline Other produced & 0.6 & NA & 30 & 3 & 31 & 0 & 0.6 & 20 & 1 & 20 \\
\hline Total $†$ & 750 & 1920 & 1820 & 590 & 4490 & 290 & 2700 & 2080 & 2990 & 5070 \\
\hline Total $7-17$ years & 270 & 520 & 300 & NA & 1100 & 110 & 740 & 250 & 850 & 1100 \\
\hline
\end{tabular}

*U, PG, 12A, 15.

$+\mathrm{G}, \mathrm{PG}$, and $\mathrm{PG}-13$.

$\ddagger$ Sums may not equal totals owing to rounding

NA, not available; data not collected on number of youths who are admitted to ' 18 ' rated films.

than in the USA for two reasons. First, in the USA conventional cigarette advertising is also contributing to youth smoking initiation, but such advertising has been all but banned in the UK, which increases the relative importance of films as a promotional medium. (Even in the $\mathrm{USA}^{26}$ and Germany, ${ }^{27}$ where promotion of tobacco products continues, the effect of films on youth smoking behaviour exceeds that of traditional advertising and promotion.) Second, because of the differences in rating practices documented in this paper, the level of adolescents' exposure to on-screen smoking is substantially higher in the UK than the USA.

In addition to lowering the probability that a youth will see a film, ${ }^{28}$ an ' 18 ' rating for smoking would create an economic incentive for motion picture producers to simply leave smoking out of films developed to be marketed to youths. By comparing total box office sales of a random sample of 40 youth-rated films with that of the 40 ' 18 '-rated films, we determined that youthrated films grossed 1.75 times as much as '18'-rated films. The decision to classify a film as appropriate for youths clearly has economic benefits for the film industry.

In the USA, one thing that paediatricians can do is advise parents to keep children and teenagers from seeing R-rated movies, thereby substantially reducing the exposure to children. ${ }^{29}$ In the USA, children of parents who restrict their access to R-rated films are less likely to smoke, in a way consistent with the observed dose-response relation. This intervention is not available to paediatricians in the UK because the BBFC rates $75 \%$ of US R-rated for children ('15' or ' 12 ').

\section{Limitations}

Our analysis is based on 572 (78\%) out of the 738 most popular films in the UK from 2001 to 2006. The films included in our sample accounted for $92 \%$ of total box office takings in that period, so our estimates of UK youths' level of exposure to onscreen smoking are likely to be low. Similarly, because the UK Film Council does not collect data for the fraction of the cinema audience aged 7-17 for '18'-rated films, we assumed that this number was zero. To the extent that youths have access to films rated '18', our results underestimate exposure.

Additionally, our estimate of tobacco impressions delivered to this age group underestimates total youth exposure, since it does

\section{What this paper adds}

Studies from the USA, New Zealand, Mexico and Germany demonstrate that exposure to smoking in movies causes youths to smoke and that there is a dose-response effect of film smoking exposure on youth smoking uptake.

- This study demonstrates that, because of differences in rating practices in the UK and USA, youths in the UK experience much heavier exposure to tobacco impressions by topgrossing films in cinematic release, suggesting that the effects of on-screen smoking as a stimulant for smoking behaviour in the UK are even larger than in the USA. A film classification policy that keeps on-screen smoking out of films rated for youths (eg, films classified 15 and below) would reduce this exposure for people under 18 years of age and probably lead to a substantial reduction in youth smoking.

not include children younger than 7 or youth exposure to cinematic tobacco imagery through video media and the internet.

\section{Conclusions}

Exposure to smoking in films accessible to youths is a substantial contributor to youth smoking initiation. UK youths are potentially exposed to even more on-screen smoking than are youths in the USA, where the strong dose-response effect is firmly established. Implementing the BBFC film rating system's current standard that films in which 'material or treatment appears ... to risk harm to individuals or, through their behaviour, to society' and assigning future films with tobacco imagery an '18' rating would reduce UK youth exposure to on-screen smoking even more than a comparable change in the USA, with a correspondingly greater reduction in films' effect on youth smoking initiation.

Acknowledgements We would like to thank the Cancer Control Research Program at Dartmouth-Hitchcock Medical Center for providing tobacco occurrences ratings for the movies in our sample. 
Funding This research was supported by Health@Work Liverpool, Liverpool Primary Care Trust, Smokefree Northwest, Roy Castle Lung Cancer Foundation and the American Legacy Foundation. CM undertook this study during a Harkness Fellowship in Health Care Policy and Practice and was supported of the Commonwealth Fund in New York. The funding agencies had no role in the conduct of the research or preparation of the manuscript.

Competiting interests None.

Contributors In addition to all authors' intellectual contributions to the conceptualisation of the study, interpretation of the data and final approval of the submitted manuscript, SJA designed the study, collected and analysed film box office data and BBFC/MPAA classification data, and co-wrote the manuscript; $\mathrm{CM}$ analysed audience composition data and commented on earlier drafts of the paper; JRP collected and analysed film studio data, provided general consultation on the structure of the film industry and commented on earlier drafts of the manuscript; and SAG co-wrote the manuscript, provided general consultation on the relevant literature and supervised the project.

Provenance and peer review Not commissioned; externally peer reviewed.

\section{REFERENCES}

1. Charlesworth A, Glantz SA. Smoking in the movies increases adolescent smoking: a review. Pediatrics 2005:116:1516-28.

2. Institute of Medicine. Ending the tobacco problem: a blueprint for the nation. Washington, DC: National Academies Press, 2007

3. BMA Board of Science. Forever cool: the influence of smoking imagery on young people. London: British Medical Association, 2008. http://www.bma.org.uk/images/ forevercool tcm41-169812.pdf.

4. National Cancer Institute. Tobacco control monograph 19: the role of the media in promoting and reducing tobacco use. Bethesda, MD: US National Cancer Institute, 2008.

5. Bridge R. Call to restrict smoking scenes. Liverpool: BBC News, 2008 [updated March 16]. http://news.bbc.co.uk/nolpda/ifs_news/hi/newsid_7298000/7298970.stm (accessed 24 April 2009).

6. Dalton MA, Sargent JD, Beach ML, et al. Effect of viewing smoking in movies on adolescent smoking initiation: a cohort study. Lancet 2003;362:281-5.

7. Laugesen M, Scragg R, Wellman RJ, et al. R-rated film viewing and adolescent smoking. Prev Med 2007;45:454-9.

8. Thrasher JF, Jackson C, Arillo-Santillan E, et al. Exposure to smoking imagery in popular films and adolescent smoking in Mexico. Am J Prev Med 2008;35:95-102.

9. Hanewinkel R, Sargent JD. Exposure to smoking in internationally distributed American movies and youth smoking in Germany: a cross-cultural cohort study. Pediatrics 2008:121:e108-17.
10. Hanewinkel R, Morgenstern M, Tanski SE, et al. Longitudinal study of parental movie restriction on teen smoking and drinking in Germany. Addiction 2008;103:1722-30.

11. Hanewinkel R, Sargent JD. Longitudinal study of exposure to entertainment media and alcohol use among German adolescents. Pediatrics 2009:123:989-95

12. Hunt K, Sweeting H, Sargent J, et al. An examination of the association between seeing smoking in films and tobacco use in young adults in the west of Scotland: cross-sectional study. Health Educ Res 2009;24:22-31.

13. World Health Organization. Smoke-free movies: from evidence to action. Geneva: World Health Organization, 2009. http://www.who.int/tobacco/smoke free movies/ en/ (accessed 16 June 2009).

14. Glantz SA. Rate movies with smoking "R.". Eff Clin Pract 2002;5:31-4.

15. British Board of Film Classification. Bbfc: '18' - suitable only for adults. London, England, 2009. http://www.bbfc.co.uk/downloads/pub/Guidelines/BBFC\% 20Classification\%20Guidelines\%202009.pdf (accessed 24 April 2009).

16. British Board of Film Classification. Bbfc: About the Bbfc. London, England, 2009 http://www.bbfc.co.uk/about/index.php (accessed 24 April 2009)

17. Innes C. Film stars "make kids start smoking". Liverpool: Liverpool Echo, 2008. http:// www.liverpoolecho.co.uk/liverpool-news/local-news/2008/03/14/film-stars-makekids-start-smoking-100252-20622559/ (accessed 24 Apr 2009).

18. City of Liverpool Licensing and Gambling Committee. Request for revision of licensing policy - smoking imagery in films 2009 June 12. Report No LAS/002/08.

19. Internet Movie Database. 2008. www.imdbpro.com laccessed 200812 March through Wednesday 19 March 2008).

20. Sargent JD, Worth KA, Beach M, et al. Population-based assessment of exposure to risk behaviors in motion pictures. Commun Methods Meas 2008;2:134-51.

21. Sargent JD, Beach ML, Adachi-Mejia AM, et al. Exposure to movie smoking: its relation to smoking initiation among US adolescents. Pediatrics 2005;116:1183-91.

22. Titus-Ernstoff L, Dalton MA, Adachi-Mejia AM, et al. Longitudinal study of viewing smoking in movies and initiation of smoking by children. Pediatrics 2008; 121:15-21.

23. Dalton MA, Beach ML, Adachi-Mejia AM, et al. Early exposure to movie smoking predicts established smoking by older teens and young adults. Pediatrics 2009;123 e551-8.

24. Song AV, Ling PM, Neilands TB, et al. Smoking in movies and increased smoking among young adults. Am J Prev Med 2007;33:396-403.

25. UK Film Council, 2008. http://www.ukfilmcouncil.org.uk (accessed 6 March 2008)

26. Glantz SA. Smoking in the movies: a major problem and a real solution. Lancet 2003; 362:258-9

27. Sargent JD, Hanewinkel R. Comparing the effects of entertainment media and tobacco marketing on youth smoking in Germany. Addiction 2009;104:815-23.

28. Sargent J, Tanski S, Gibson J. Exposure to movie smoking among US adolescents aged 10 to 14 years: a population estimate. Pediatrics 2007:119:e1167-76.

29. Sargent JD, Beach ML, Dalton MA, et al. Effect of parental R-rated movie restriction on adolescent smoking initiation: a prospective study. Pediatrics 2004:114:149-56. 